\title{
ANÁLISE HISTÓRICA DO PARQUE DO POVO DE PRESIDENTE PRUDENTE - SP
}

Annye Montagnini Casetta, Bárbara Kushikawa Silva, Danielly de Albuquerque, Vanessa Rodrigues Ventura, Yeda Ruiz Maria

Universidade do Oeste Paulista - UNOESTE, curso de Arquitetura e Urbanismo, Presidente Prudente, SP. E-mail: yedarm@hotmail.com

\section{RESUMO}

O Parque do Povo, espaço público de Presidente Prudente - SP possui grande relevância para o município, sendo visto como o cartão postal da cidade. Sua concepção afetou diretamente a configuração da cidade na época em que foi projetado, tanto geograficamente quanto socialmente, além dos diversos interesses políticos e econômicos. Atualmente, é um ambiente que possui forte relação com os prudentinos, seja por suas atividades, seja com suas partes físicas, agregando significados à sua imagem. $O$ objetivo desse levantamento visa transmitir parcialmente, uma releitura histórica do Parque do Povo e da sua concepção para a compreensão da sua importância e configuração nos dias atuais. Faz-se necessário um levantamento documental para compreensão e organização dos fatos históricos e levantamento in loco para observações das características atuais.

Palavras-chave: Releitura Histórica; Especulação Imobiliária; Parque do Povo; Presidente PrudenteSP.

\section{HISTORICAL ANALYSIS OF PARQUE DO POVO OF PRESIDENTE PRUDENTE - SP}

\section{ABSTRACT}

The Park of the People, public space of Presidente Prudente - SP has great relevance for the municipality, being seen as the postcard of the city. His conception directly affected the configuration of the city at the time it was designed, both geographically and socially, in addition to the various political and economic interests. Today, it is an environment that has a strong relationship with the prudentinos, either by their activities or their physical parts, adding meanings to their image. The aim of this survey is to partially transmit a historical re-reading of the People's Park and its design to understand its importance and configuration in the present day. It is necessary a documentary survey to understand and organize the historical facts and survey in loco for observations of the current characteristics.

Keywords: Historical Re-reading; Real Estate Speculation; Parque do Povo; Presidente Prudente-SP.

\section{INTRODUÇÃO}

A população de Presidente Prudente - SP tem o Parque do Povo como a principal área de lazer pública disponível, esta qualificada ao longo do tempo com reformas e reestruturações. Apesar de algumas deficiências atuais, a imagem do parque é positiva para a maioria dos seus usuários. Segundo Lynch (1960) a imagem da cidade é o que fica gravado na mente das pessoas, fazendo com que cada indivíduo consiga se orientar, apresentando então relação direta com o emocional.

O presente trabalho traz como estudo de caso o Parque do Povo da cidade de Presidente Prudente - SP, uma centralidade urbana que atualmente possui densidade comercial, oque atrai e induz fluxos sociais de pessoas e automóveis, instigando a diversidade uso e ocupação do solo. 
Para tanto se faz necessário levantamento documental para compreensão e organização dos fatos históricos e levantamento in loco para observações das características atuais.

\section{UM POUCO DE HISTÓRIA - O PARQUE DO POVO DE PRESIDENTE PRUDENTE - SP}

A cidade de Presidente Prudente - SP, localizada na porção oeste do Estado de São Paulo, exerce papel de polo regional para os municípios de seu entorno, atraindo e centralizando diversas formas de serviços em seu raio de influência.

O Parque do Povo é um espaço público de lazer, localizado no município de Presidente Prudente - SP. O mesmo se estende desde a Avenida Manoel Goulart até a Avenida Brasil, se posicionando entre duas vias arteriais da cidade: as avenidas 11 de Maio e 14 de Setembro (FIGURA 1).

FIGURA 1 - Mapa de Presidente Prudente no estado de São Paulo com destaque para o Parque do Povo e as ruas de acesso.

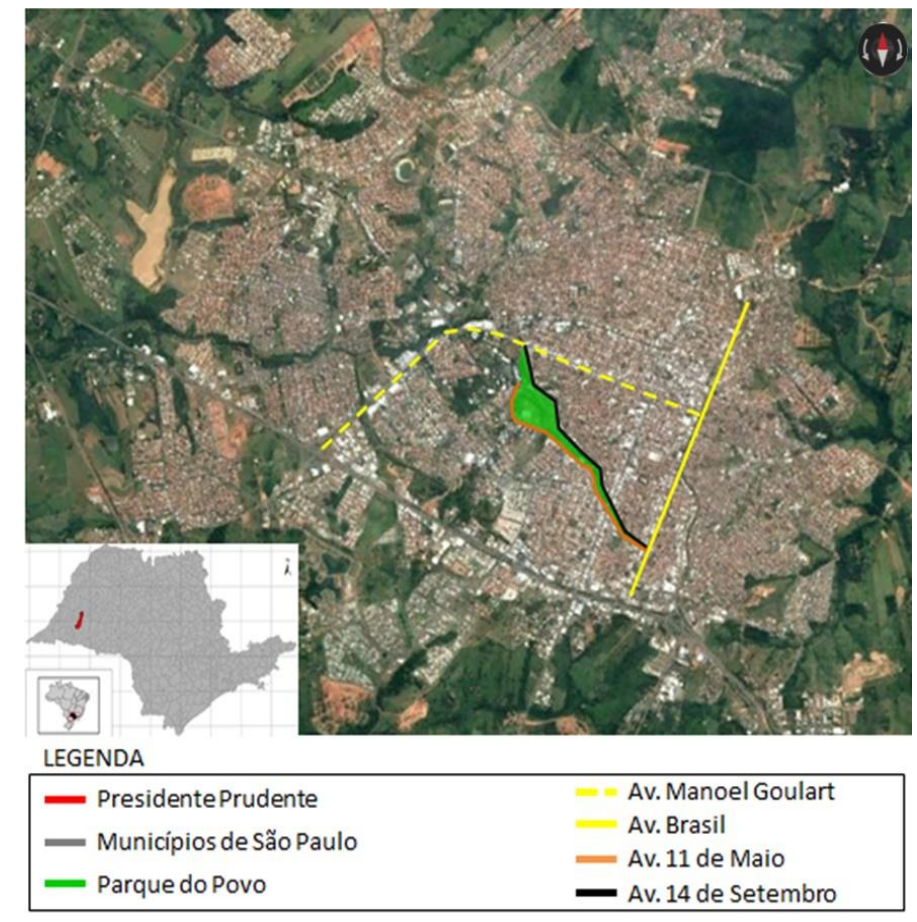

Fonte: Google Earth, 2016. Editada pelas autoras, 2017.

Segundo Sposito (1983), é possível observar que a expansão da malha urbana de Presidente Prudente - SP aconteceu entre 1940 e 1980, sendo que a ocupação do Parque do Povo e seu entorno ocorreu de forma mais efetiva entre as décadas de 1960 a 1980.

A área de lazer de uso público se situa sobre um fundo de vale (atualmente canalizado) que antes de ser implantado, desafiava a administração pública. A área foi construída em 1970 com recursos doados pelo Governo Federal de forma a mudar a fisionomia da cidade que parecia parar naquele local, sem chance de crescimento (SILVA, 1994).

O projeto do Parque do Povo surgiu em consequência de diversos interesses políticos, até pelo fato de ter sido apresentado em um contexto de eleições municipais em 1976 (HORA, 1991). Denominado "Fundo de Vale", o projeto foi apresentado à população da cidade, ainda no ano de 1976 pela Prefeitura Municipal de Presidente Prudente - SP (VAZ, 1999).

O projeto propunha implantar um parque em um fundo de vale por onde passa o Córrego do Veado, alegando uma necessidade de recuperar esta área degradada que configurava uma 
barreira física na circulação entre o centro da cidade e os bairros localizados além dele, rumo à rodovia Raposo Tavares (SAWADA et al., 2007).

Primeiramente, a obra implantaria duas avenidas, atualmente 11 de Maio e 14 de Setembro, ligando as avenidas Brasil e Manoel Goulart, ladeando o retratado córrego, em uma distância que viria a receber uma série de equipamentos de lazer para a população. Além disso, o projeto também promoveria a canalização do córrego entre as avenidas, até se encontrar com o Córrego da Colônia Mineira (próximo ao Prudenshopping) (SILVA, 1994).

O projeto foi financiado pelo Fundo de Desenvolvimento Urbano - F.D.U., repassado pelo Banco do Brasil e do Departamento Nacional de Obras e Saneamento - D.N.O.S. Em seguida, após o início das obras, o projeto passou receber recursos da Comunidade Urbana para Recuperação Acelerada - CURA, um dos programas de financiamento do extinto Banco Nacional da Habitação BNH, do regime militar (SILVA, 1994).

Assim, uma situação delicada e mal resolvida de desapropriação (poder público versus moradores e proprietários) se iniciou, porém não impediu o início das obras que ocorreu em 31 de outubro de 1976 (SILVA, 1994).

O Parque do Povo foi inaugurado em 1982 apesar de não estar completamente concluído. Em 1983, um ano depois de sua inauguração, a obra foi abandonada pela administração municipal por se mostrar demasiadamente dispendiosa e por não solucionar o problema das inundações nessa área (VAZ, 1999).

No ano de 1995, a Prefeitura Municipal de Presidente Prudente - SP, com o auxílio da Companhia Prudentina de Desenvolvimento - PRUDENCO, deu início à substituição da canalização aberta do Córrego do Veado, na extensão que abrange o Parque do Povo, pela canalização fechada. As obras de substituição por tubos armicos corrugados acarretaram custos de aproximadamente cinco milhões de reais, sendo executadas em 14 etapas (SILVA, 1994).

É importante ressaltar que as reformas se intensificaram ao longo dos anos, oferecendo diversas atividades possíveis para o diversificado público que frequenta o parque com diferentes intencionalidades.

De acordo com Brustelo (2013), a implantação do Prudenshopping em 1990 trouxe um novo padrão de consumo, que até então não existia em Presidente Prudente - SP. É importante ressaltar que o empreendimento contou com incentivo do Poder Público Municipal, trazendo a reflexão de que não foi implantado naquele local por acaso, mas sim de forma premeditada, colocando em foco a reestruturação daquela porção da cidade.

Este espaço passou a configurar uma nova centralidade urbana na cidade, apresentando uma nova concentração de atividades econômicas, com uma elevada densidade de estabelecimentos comerciais e por induzir um maior volume de fluxos no horário comercial.

Neste contexto se entende que a implantação daquele equipamento de consumo e lazer é ação ditada pelos rumos do capital, e que privilegiou principalmente os cidadãos que possuem maior poder aquisitivo e influência política na cidade, que residem em seu entorno imediato.

Desta forma, a "mancha de lazer" que se encontra nesta área, resultou deste processo, que direcionava á uma maior segregação do espaço urbano prudentino, quando foi criado todo um conjunto de equipamentos e infraestrutura com foco para o entorno imediato das classes mais altas da cidade.

Em 2001, a Prefeitura Municipal de Presidente Prudente - SP pediu sugestões à população ao lançar uma campanha de revitalização do Parque do Povo. Para isto utilizaram um encarte distribuído por um jornal da cidade: "Esta campanha visava tornar mais belo o maior espaço público e de lazer do município. Vamos transformá-lo num cartão postal. Participe!" (19/out.2001).

Desta forma, no ano de 2002 iniciaram diversas obras de revitalização do parque, que incluíam ampliação das calçadas, dos estacionamentos, do parque infantil, e implantação dos campos de areia, pista para bicicletas e circuitos de exercícios (BORTOLO, 2013b.) 
Ampliou de forma significativa a iluminação, além de implantar quiosques comerciais, postos policiais e substituir a tubulação da canalização, além de incrementar vegetação em alguns pontos (SOBARZO, 2005).

Segundo Sposito (1983), ocorreu uma grande mudança no perfil de pessoas que ocupavam os loteamentos adjacentes ao Parque do Povo, quando uma parcela da população de alto poder aquisitivo substituiu parte de seus primeiros habitantes, que eram em sua maioria de classe baixa, uma vez que estes não apresentavam mais condições de arcar com os novos custos tributários gerados pelas melhorias da área (a implantação do parque e ampliações da pavimentação asfáltica). Estas dinâmicas de produção espacial urbana evidenciam o poder de influência do poder público no que diz respeito à sustentação de interesses socioeconômicos privados.

Em 2014, o Parque do Povo, passou por mais um processo de revitalização, sendo inaugurado em 17 de dezembro de 2015. De acordo com a Prefeitura Municipal de Presidente Prudente - SP, a obra no local demandou um ano e três meses. Ao todo, foram investidos R\$ 3 milhões com recursos do governo do Estado de São Paulo.

\section{O PARQUE DO POVO ATUALMENTE}

Atualmente, o Parque do Povo representa o espaço público de maior convivência na cidade de Presidente Prudente - SP, tendo usos múltiplos ao longo do dia e dos dias da semana.

As vias adjacentes ao parque estão recebendo cada vez mais lojas, comércios, restaurantes, bares, academias e edifícios residenciais de alto padrão. Devido essa capacidade de concentrar e atrair atividades e pessoas, esse processo de adensamento no local, consequentemente, traz mais investimentos econômicos, o que acaba gerando a especulação imobiliária, além de reorganizar os fluxos que percorrem a cidade: as Avenidas 11 de Maio e 14 de Setembro que margeiam o parque são algumas das vias principais da cidade, oferecendo uma conexão entre as Avenidas Manoel Goulart e Brasil, com um fluxo intenso durante todo o dia.

Sua localização é uma das áreas mais valorizadas da cidade, com grande parte da classe média/alta prudentina habitando seus arredores. Configura um entorno com grande densidade de edificações e uma evidente verticalização.

O parque conta com infraestrutura de qualidade e ambientes agradáveis com uma extensa área verde. Apesar disso, existem problemas com a iluminação noturna em alguns pontos de sua extensão que consequentemente geram insegurança. Há também o decorrente problema dos dias chuvosos, onde alguns pontos do parque ficam intransitáveis devido aos alagamentos.

Por ser uma centralidade urbana, ele influencia no uso e ocupação do solo de seu entorno, criando problemas de especulação imobiliária, evidente no alto custo do aluguel destes espaços e de lotes vazios esperando serem valorizados.

Em demasia, o espaço interfere na hierarquia viária da cidade, criando congestionamentos e conflitos de fluxos. Desta forma tem-se que de todas as qualidades deste espaço, os incontáveis problemas, se não tratados, com o devido cuidado, acarretarão um consequente processo de deterioração.

\section{CONCLUSÃO}

Os usos diferenciados do espaço do Parque do Povo mostram a partir das práticas sociais, mudanças nas funções do lugar e na centralidade, além das mudanças de característica econômica, social e funcional no próprio município. Não obstante, é inegável a importância da história do Parque do Povo, que inclui diversas condicionantes essenciais que resultam em sua conformação simbológica nos dias de hoje. 


\section{REFERÊNCIAS BIBLIOGRÁFICAS}

BARRETO NETTO, Adolpho. Centralidades do lazer em Presidente Prudente: fluxos, tensões e territorialidades no Parque do Povo. 2016. 1 CD-ROM. Trabalho de conclusão de curso (bacharelado - Geografia) - Universidade Estadual Paulista, Faculdade de Ciências e Tecnologia, 2016. Disponível em: <http://hdl.handle.net/11449/139296>.

BORTOLO, Carlos Alexandre De. 0 espaço público do parque do povo - Presidente Prudente-SP: reflexões geográficas. Geografia em atos, Presidente Prudente, v. 1, n. 13, p. 50-65, jun. $2013 a$.

BORTOLO, Carlos Alexandre De. A produção das cidades, novos olhares e suas configurações: o Parque do Povo no contexto de Presidente Prudente-SP. Presidente prudente, ago. 2013b.

BORTOLO, Carlos Alexandre De. 0 parque do povo em Presidente Prudente-SP: usos e apropriações de um espaço público. Percurso - NEMO, Maringá, v. 5, n. 2, p. 47-71, 2013c.

G1 GLOBO. Após mais de um ano, revitalização do parque do povo é entregue. Disponível em: <http://g1.globo.com/sp/presidente-prudente-regiao/noticia/2015/12/apos-mais-de-um-anorevitalizacao-do-parque-do-povo-e-entregue.html>. Acesso em: 17 mar. 2017.

MENEZES, Vitor Ruiz. Paisagem urbana parque do povo - Presidente Prudente. Presidente Prudente: UNOESTE, 2016.

SILVA, Maria José Martinelli. O Parque do Povo em Presidente Prudente-SP: a lógica da intervenção do poder público local no processo de (re) estruturação do espaço urbano. Presidente Prudente, 1994.

SOBARZO MIÑO, Oscar Alfredo. Os espaços da sociabilidade segmentada: a produção do espaço público em Presidente Prudente. 2005. 221 f. Tese (doutorado) - Universidade Estadual Paulista, Faculdade de Ciências e Tecnologia, 2005. Disponível em: <http://hdl.handle.net/11449/105050>.

XAVIER, Fernanda Berguerand. Qualidade Urbana Ambiental e Prática de Atividades Físicas: Um Estudo Sobre o Parque do Povo de Presidente Prudente SP. 2016. 116 f. Dissertação (Mestrado em Ciências Ambientais) - Universidade do Oeste Paulista, Presidente Prudente, 2016. 